\title{
Dislexia: A contribuição da Psicopedagogia no que se refere aos distúrbios de aprendizagem que afeta o desenvolvimento da leitura e da escrita.
}

(Dyslexia: The contribution of Psychopedagogy with regard to learning disorders that affects the development of reading and writing.)

\author{
Marta Elizete Buchelt Rech \\ Escola Municipal de Educação Básica Lizamara A. Oliva de Almeida-MT-Brasil. \\ Maria dos anjos Miranda \\ Escola Estadual Professor Djalma Guilherme da Silva-MT-Brasil.
}

Fecha recepción: 01-04-2018

Páginas 131-143

Fecha aceptación: 30-06-2018

\section{Resumo.}

O presente trabalho buscou aprofundar estudos sobre a dislexia a qual afeta a aprendizagem tanto na leitura como na escrita. Dislexia, termo este que se faz necessário compreender o real conceito para não cair na tendência generalizadora ainda vista atualmente. Para tanto, faz-se necessário entender o distúrbios da aprendizagem nos mais variados aspectos, pois, podem prejudicar muito 0 aluno neste processo. A pesquisa teve cunho qualitativo do tipo bibliográfico. Assim, salienta-se que para aprenda a ler e a escrever a criança precisa desenvolver novas habilidades que a represente desde as novas formas de interagir junto a leitura $e$ escrita. Contudo, os educadores possuem a função primordial de serem os mediadores neste processo de aquisição de conhecimento, a complexidade tanto na linguagem como na escrita e muitas das vezes se faz necessária a intervenção do psicopedagogo(a) para atuar com mais segurança para que o problema seja amenizando.

Palavra-chave: dislexia; distúrbio; leitura; escrita; aprendizagem.

\begin{abstract}
.
The present work sought to deepen studies on dyslexia, which affect learning in both reading and writing. Dyslexia, a term that makes it necessary to understand the real concept so as not to fall into the generalizing tendency still seen today. To do so, it is necessary to understand the learning disorders in the most varied aspects, as they can greatly harm the student in this process. The research had qualitative characteristics of the bibliographic type. Thus, it is emphasized that in order to learn to read and write the child needs to develop new skills that represent it from the new ways of interacting with reading and writing. However, educators have the primary function of being the mediators in this process of knowledge acquisition, the complexity in both language and writing and often the intervention of the psych pedagogue (a) is necessary to act more safely so that the problem be softening.
\end{abstract}

Keyword: dyslexia; disabilities; reading; writing; learning. 


\section{1.-Introdução.}

O domínio da leitura e da escrita corresponde a um dos fatores básicos para que ocorra o desenvolvimento escolar, uma vez que é sobre tais capacidades que se darão as aprendizagens futuras. Alterações no processo de aquisição da escrita podem privar a criança de ter acesso a uma série de conhecimentos, e consequentemente, dificultar sua evolução escolar, o que acaba por causar danos evidentes tanto no plano afetivo quanto social.

O termo dislexia, ainda, tem sido tradicionalmente empregado para procurar descrever o caso daquelas crianças que, mesmo sem motivos mais evidentes, não conseguem desenvolver-se no que diz respeito ao aprendizado da leitura-escrita. Dessa forma, dislexia refere-se, às dificuldades para o aprendizado da leitura-escrita em razão de causas que ainda não são claramente conhecidas.

A primeira parte do estudo destaca-se a Psicopedagogia, sua origem, qual é o seu real conceito, mostrando assim, que ela é parte integrante do processo ensinoaprendizagem. Na segunda parte é apresentado um Plano de Tratamento para as Dificuldades da Leitura-escrita, tentando assim, solucionar as dificuldades que impedem ou dificultam o desenvolvimento normal deste processo.

Para discutir a questão o problema: Como identificar o (distúrbio-dislexia) no ensinoaprendizagem que afeta diretamente o domínio da leitura-escrita? Enquanto objetivo geral: Conhecer esse distúrbio de aprendizagem nos mais variados aspectos.

Assim sendo elencou-se os objetivos específicos:

1) Compreender os mais variados aspectos do distúrbio que afeta o desenvolvimento da leitura e escrita.

2) identificar para inferir nos problemas de aprendizagem na leitura e na escrita.

3) Reconhecer a necessidade do(a) Psicopedagogo(a) nas intervenções educacionais.

Pode se dizer que a criança não escolhe ir para a escola e, tampouco, o que vai aprender. A instituição escolar tem a função de preparar a criança para ingressar na sociedade, promovendo as aprendizagens necessárias para o grupo social ao qual ela está inserida. Na escola a crianças encontram-se com 0 outro 0 professor. Que por sua vez escolheu a tarefa de ensinar o que sabe.

A grande motivação leva o professor a eleger essa tarefa à qual pode ser muito variadas. Para pensar na motivação dessa escolha, podemos perguntar: 0 que ensinar e, para que ensinar? O que ensinar? A quem ensinar? Para alguns profissionais pode representar a necessidade de transmitir, de dar ao outro o que sabe, a partir das próprias ações sobre o mundo físico e social. O professor necessariamente precisa estar munido de conhecimento para uma verdadeira apropriação do saber, caso contrário não poderá acompanhar o aluno no caminho da construção do conhecimento. 
Deste modo, os profissionais engajados no campo da Psicopedagogia têm atentado para a necessidade do trabalho a ser realizado na instituição escolar. Portanto, se faz necessário pensar a escola à luz da Psicopedagogia, o que significa analisar processo que inclui questões metodológicas, relacionais e socioculturais, englobando o ponto de vista de quem ensina e de quem aprende abrangendo a participação da família e da sociedade. $O$ aluno ao ingressar no ensino regular, por volta dos 7 anos, traz consigo uma história vivida dentro do seu grupo familiar. Uma vez que sua história tenha transcorrido sem maiores consequências, poderá também ter uma relação com o conhecimento maneira mais favorável.

\section{2.-Fundamentação teórica.}

\section{1.-Concepção da psicopedagogia.}

A Psicopedagogia surgiu a partir da inquietação e insatisfação dos profissionais que tratavam das dificuldades de aprendizagem. A ênfase estava em afastar 0 mal funcionamento por meio de uma boa ensinagem, e, como consequência, 0 aprendiz poderia integrar-se voltando a aprender normalmente. A definição da psicopedagogia passou por diferentes momentos históricos, onde o objeto de estudo era o sujeito que não podia aprender e este por sua vez era carregado de significados.

Inicialmente, o termo psicopedagogia havia sido empregado para refletir-se à aplicação de conhecimentos da psicologia e da pedagogia. Se refletirmos sobre 0 seu significado atual, podemos perceber que essa explicação não condiz com o que os psicopedagogos pensam a respeito da psicopedagogia. O conceito da psicopedagogia mais recente surge com base no diálogo, que os profissionais que se dedicavam a tratar as dificuldades de aprendizagem estabeleceram com diferentes áreas do conhecimento, como: psicologia cognitiva, psicanálise, sociologia, linguística, antropologia, filosofia, entre outras, ou seja o termo psicopedagogia é empregado para referir-se a um corpo teórico que define a aprendizagem como seu objeto de estudo.

Dessa forma Scoz (1992: 2) afirma que a Psicopedagogia estuda o processo de aprendizagem e suas dificuldades, e numa ação profissional deve englobar vários campos do conhecimento, integrando-os e sintetizando-os. No entanto para Fagali (1994, p. 9), a psicopedagogia surgiu como necessidade de compreender os problemas de aprendizagem, refletindo sobre as questões relacionadas ao desenvolvimento cognitivo, psicomotor e afetivo, implícitas nas situações de aprendizagem.

Atualmente suas contribuições extrapolam as questões relacionadas apenas aos problemas se dirigem para duas vertentes: a psicopedagogia curativa ou terapêutica e a psicopedagogia preventiva. A psicopedagogia curativa ou terapêutica tem como objetivo reintegrar ao processo de construção de conhecimento uma criança que apresente problemas de aprendizagem. Ela tem se desenvolvido nos consultórios onde 0 trabalho tem uma conotação clínica, individual. Mas estas práticas têm sido 
reformuladas para o trabalho em grupo, no contexto institucional como creches, escolas, centros de reabilitação e hospitais.

Enquanto a psicopedagogia preventiva tem como meta refletir e desenvolver projetos pedagógico-educacionais, enriquecendo os procedimentos em sala de aula, as avaliações e planejamentos na educação sistemática e assistemática, ou seja, considerando o trabalho na instituição escolar a psicopedagogia preventiva, refere-se à assessoria junto a pedagogos, orientadores e professores, já a curativa é reintegrar e readaptar 0 aluno e também desenvolver funções cognitivas integradas ao afetivo.

Segundo Bossa (1994, p. 24) a psicopedagogia nasceu para atender a patologia da aprendizagem, mas ela se tem voltado cada vez mais para uma ação preventiva, acreditando que muitas dificuldades de aprendizagem se deve à inadequada Pedagogia institucional e familiar A proposta da Psicopedagogia numa ação preventiva é adotar uma postura crítica frente ao fracasso escolar, numa concepção mais totalizante, visando propor novas alternativas de ação voltadas para a melhoria da prática pedagógica nas escolas.

A escola é com efeito, a grande preocupação da psicopedagogia em seu compromisso de ação preventiva pois este campo é muito amplo, mas pouco explorado. Grande parte da aprendizagem ocorre dentro da instituição escolar, na relação com professor, com o conteúdo e com o grupo social escolar enquanto um todo. Sendo assim, o trabalho preventivo em psicopedagogia consiste na pesquisa das condições necessárias para que se produza a aprendizagem dos conteúdos escolares, identificando seus obstáculos e seus elementos facilitadores.

Assim Bossa (1994, p. 66), afirma que o trabalho psicopedagógico, pode e deve ser pensado a partir da instituição escolar, a qual cumpre uma importante função social: a de socializar os conhecimentos disponíveis promover o desenvolvimento cognitivo e a construção de regras de conduta dentro de um projeto social mais amplo $\mathrm{A}$ escola afinal é responsável por grande parte da aprendizagem do ser humano.

A escola é responsável pela aprendizagem sistemática segundo Visca (1988, p. 78) quando afirma que a aprendizagem sistemática é aquela que se opera na interação com as instituições educativas, mediadoras da sociedade, órgãos especializados para transmitir os conhecimentos, atitudes e destrezas que a sociedade estima necessárias para a sobrevivência, capazes de manter uma relação equilibrada entre a identidade e a mudança.

Assim sendo pensar a escola à luz da Psicopedagogia implica nos debruçarmos especialmente sobre a formação do professor. Bossa (1994, p. 71) diz que a tarefa mais importantes na ação Psicopedagógica é encontrar novas modalidades para tornar essa formação mais eficiente. Assim, pois, as propostas de formação docente devem oferecer ao professor condições para estabelecer uma relação madura e saudável com seus alunos, pais e autoridades escolares, conforme a eterna 
reformulação dos saberes, que se acredita sejam importantes para a vida dos homens em sociedade

Pensar no trabalho clínico, que se dá nos consultórios ou em hospitais, o psicopedagogo busca não só compreender o porquê do aprendiz não aprender, mas o que ele pode aprender e como. A busca desse conhecimento inicia-se no processo de diagnóstico. O diagnóstico psicopedagógico é um processo, um contínuo sempre revisável, onde a intervenção do psicopedagogo inicia, numa atitude investigadora, até a intervenção, com o objetivo da observação ou acompanhamento da evolução do aprendiz. Assim o tratamento requer procedimentos específicos que constituem a metodologia.

O trabalho clinico acontece em dois momentos especiais: a fase diagnóstica, com testes a servir de pistas para 0 saber e a fase de intervenção. A esse respeito Sara Pain (1992, p. 69) nos diz que o Diagnosticar não aprende como sintoma consiste em encontrar sua funcionalidade, isto é, sua articulação na situação integrada pelo paciente e seus pais. Desta forma, o eixo do diagnóstico será a articulação do sintoma, o sentido da ignorância no triângulo edípico.

E mais à frente continua sara Pain (1992, p. 72) diz que o tratamento começa com a primeira entrevista diagnóstica, já que o enfrentamento do paciente com sua própria realidade, realidade esta que provavelmente nunca precisou se organizar em forma de discurso, o obriga a uma série de aproximações, avanços e retrocessos mobilizadores de um conjunto de sentimentos contraditórios. Os poucos assinalamentos realizados pelo psicólogo para orientar o motivo de consulta e a história vital, bem como as perguntas destinadas a confirmar ou descartar hipóteses plausíveis, chegam a ser para 0 paciente descobertas deslumbrantes e desencadeadoras de uma série de lembranças e de esquecimentos injustificáveis.

\section{2.-Dificuldade de aprendizagem.}

É de suma importância o papel dos educadores pais e professores nos processos fundamentais do desenvolvimento humano. É a família quem primeiro proporciona experiências educacionais à criança, no sentido de orientá-la e dirigi-la. Os pais e os professores estão sempre ensinando simultaneamente em diferentes níveis de consciência, e as crianças estão sempre aprendendo em diferentes níveis.

$\mathrm{Na}$ escola, o professor deve estar sempre atento às etapas do desenvolvimento do aluno, portanto, é de suma importância que o professor conheça o processo de aprendizagem e esteja interessado nas crianças como seres humanos em desenvolvimento. Os problemas de aprendizagem que podem ocorrer tanto no início como durante o período escolar surgem em situações diferentes para cada aluno, 0 que requer uma investigação no campo em que eles se manifestam.

Qualquer problema de aprendizagem implica amplo trabalho do professor junto à família da criança, para analisar situações e levantar características, visando descobrir o que está representando dificuldade ou empecilho para que 0 aluno 
aprenda. É importante ressaltar que, se o professor não conhece as manifestações próprias do pensamento infantil para as várias faixas etárias, terá dificuldades em identificar o estágio em que 0 aluno se encontra, podendo incorrer em erros de, por exemplo, considerar o animismo e o egocentrismo de um pré-escolar como problemas.

Os problemas de aprendizagem referem-se às situações difíceis enfrentadas pela criança normal e pela criança com um desvio do quadro normal, mas com expectativa de aprendizagem a longo prazo (alunos multirrepetentes). Segundo Sara Pain um Diagnóstico e tratamento dos problemas de aprendizagem (1985, p. 28) pode-se considerar o problema de aprendizagem como um sintoma, no sentido de que 0 não-aprender não configura um quadro permanente, mas ingressa numa constelação peculiar de comportamentos, nos quais se destaca como sinal de descompensação.

Pela intensidade com que se apresentam os sintomas e comportamentos infantis, pela duração que eles têm na vida escolar e pela participação do lar e da escola nos processos problemáticos, fica difícil para o professor diferenciar um distúrbio de um problema de aprendizagem.

Portanto não é fácil encontrar uma definição clara e abrangente para designar problemas de aprendizagem. Esse enfoque surgiu com maior intensidade por volta dos séculos XVIII e XIX, com o grande desenvolvimento das ciências médicas e biológicas, especialmente da Psiquiatria. Mais tarde, o conceito de "anormalidade" começou a ser transferido dos hospitais para as escolas: crianças que não acompanhavam seus colegas na aprendizagem passaram a ser designadas como "anormais escolares", já que seu fracasso era atribuído a alguma anormalidade orgânica.

A ênfase nos aspectos afetivos da aprendizagem acabou levando os psicopedagogos a utilizarem um número exagerado de testes e de instrumentos de mensuração, na tentativa de encontrar pistas que os conduzissem a um diagnóstico. Portanto, estabelecer claramente os limites que separam problemas de aprendizagem dos chamados "distúrbios" de aprendizagem é uma tarefa muito complicada, que fica a critério do especialista na área em que a deficiência se apresenta.

Ao educador cabe apenas detectar as dificuldades de aprendizagem que aparecem em sua sala de aula, principalmente nas escolas mais carentes, e investigar as causas de forma ampla, que abranja os aspectos orgânicos, neurológicos, mentais, psicológicos adicionados à problemática ambiental em que a criança vive.

Existem inúmeros fatores que podem desencadear um problema de aprendizagem. São considerados fundamentais:

- Fatores orgânicos: Saúde física deficiente, falta de integridade neurológica (sistema nervoso doentio), alimentação inadequada etc. 
- Fatores psicológicos: Inibição, fantasia, ansiedade, angústia, inadequação à realidade, sentimento generalizado de rejeição etc.

- Fatores ambientais: 0 tipo de educação familiar, o grau de estimulação que a criança recebeu desde os primeiros dias de vida, a influência dos meios de comunicação etc.

Tanto o psicopedagogo como o educador não pode esquecer de que o aluno é um ser social com cultura, linguagem e valores específicos aos quais ele deve estar sempre atento, inclusive para evitar que seus próprios valores não impeçam de auxiliar a criança no seu processo de aprender. A criança é um todo e, quando apresenta dificuldades de aprendizagem, precisa ser avaliada em seus vários aspectos.

A proposta do sistema educacional brasileiro é dar, para cada criança, a oportunidade de aprender tanto quanto sua capacidade permitir. No entanto, os alunos que apresentam distúrbios ou problemas de aprendizagem considerados como um grupo significativo, não têm essa oportunidade. Eles não conseguem acompanhar o currículo estabelecido pelas escolas e, porque fracassam, são classificados como retardados mentais, emocionalmente perturbados ou simplesmente rotulados como alunos fracos e multirepetentes. São crianças que precisam de um atendimento especializado e o sistema educacional brasileiro não tem lugar para elas.

Diante desta realidade procuraremos enfocar a dislexia como um distúrbio específico do indivíduo em lidar com os símbolos (letras e/ou números), para que esse indivíduo possa ser ajudado pelos professores na sala de aula. Os disléxicos precisam de tratamento especializado tanto quanto outros deficientes na área de linguagem, mas precisam, e muito, do auxílio do professor.

\section{3.-Dislexia: Distúrbio de aprendizagem.}

De acordo com Dacroce e Nicoli (2014), os distúrbios de aprendizagem na área da leitura e da escrita podem ser atribuídos às mais variadas causas.

Orgânicas: cardiopatias, deficiências sensoriais (visuais, auditivas), deficiências motoras (paralisia infantil, paralisia cerebral) deficiências intelectuais (retardamento mental ou diminuição intelectual) e outras enfermidades de longa duração.

Psicológicas: desajustes emocionais provocados pela dificuldade que a criança tem de aprender, o que gera ansiedade, insegurança e a autoconceito negativo.

Pedagógicas: métodos inadequados de ensino, falta de estimulação pela pré-escola dos pré-requisitos necessários à leitura e à escrita; falta de percepção, por parte da escola, do nível de maturidade da criança, iniciando uma alfabetização precoce; relacionamento professor-aluno deficiente; não domínio do conteúdo e do método por parte do professor; atendimento precário das crianças devido a superlotação das classes. 
Socioculturais: falta de estimulação (criança que não faz a pré-escola e também não é estimulada no lar); desnutrição; privação cultural do meio; marginalização das crianças com dificuldades de aprendizagem pelo sistema de ensino comum.

Dislexia: um tipo de leitura que colocamos como causa porque provoca dificuldade específica na aprendizagem da identificação dos símbolos gráficos, embora a criança apresente inteligência normal, integridade sensorial e recebe estimulação e ensino adequados.

Muitas são as causas descritas sobre as crianças disléxicas. Umas das causas mais discutidas dizem respeito a déficits visuais ou auditivas, a um domínio pouco desenvolvido de fala e linguagem, a déficits neurológicos, a problemas gerais de saúde, a imaturidade, a fatores emocionais, familiares e sociais. E atualmente aponta-se para os métodos escolares e da postura pouco estimulante de muitos professores.

Devido à falta de informação dos pais, dos professores da pré-escola e à dificuldade de se identificar os "sintomas" antes da entrada da criança na escola, a dislexia só vai ser diagnosticada quando a criança estiver na $1^{\mathrm{a}}$ ou $2^{\mathrm{a}}$ série do ensino Fundamental. Nesse sentido, a dificuldade na leitura significa apenas o resultado final de uma série de desorganizações que a criança já vinha apresentando no seu comportamento pré-verbal, e em todas aquelas funções básicas necessárias para 0 desenvolvimento da recepção, expressão e integração à função simbólica, podendo ser tanto a nível visual quanto auditiva.

A dislexia, pois, segundo Antunha (2014), citado por Antunha (folheto $n^{\circ}$.6, série ABD da Associação Brasileira de Dislexia s/d.). Representando um déficit na capacidade de simbolizar, começa a se definir a partir da necessidade que tem a criança de lidar receptivamente ou expressivamente com representação da realidade, ou antes, com a simbolização da realidade, ou poderíamos também dizer, com a nomeação do mundo.

Porém, na maioria das vezes, crianças com problemas de leitura mostra um padrão de desenvolvimento normal, não apresentam qualquer lesão cerebral aparente, frequentemente se saem bem na escola em outros assuntos que não a leitura. Apresenta ainda todos os requisitos necessários para uma boa aprendizagem: boas condições familiares, sociais econômicas, oportunidades escolares adequadas, nível normal de inteligência, ausência de comprometimentos físicos e/ ou emocionais significativas. Porém, apresentam dificuldades para dominar a escrita e a leitura.

O uso do conceito de dislexia tem provocado muita confusão e controvérsia até aos dias atuais. Os primeiros pesquisadores do problema começaram empregando conceitos como dislexia, cegueira verbal, estrefossimbolia, legastema e muito outros para se referirema tal problema da leitura-escrita. 
Assim sendo, distúrbios de aprendizagem de ordens diferentes, que podem estar afetando a leitura e a escrita de diferentes maneiras, passaram a ser sinônimos de dislexia. Porém, parece ter passado despercebido que, se por um lado a dislexia pode ser considerada como um tipo específico de distúrbio de aprendizagem, por outro lado, os distúrbios de aprendizagem não se limitam à dislexia. Na verdade, tal equívoco decorre de um problema de inclusão de classes, ou melhor, uma parte (a dislexia) está sendo confundida com todo (os distúrbios de aprendizagem).

Em razão de tal conceito estar unida sendo considerado de pouco conhecimento preciso, tem-se preferido o uso do termo distúrbio de leitura-escrita, referindo-se a uma classe abrangente de dificuldades, dentre elas está a dislexia. Cientificamente não há ainda uma compreensão mais detalhada sobre este termo, abrangendo desde problemas específicos de inversão da ordem das letras dentro de uma palavra, até grandes dificuldades para compreender e memorizar um texto lido. 0 Brasil, não conseguiu fugir de tal tendência supergeneralizada. E quando este termo começou a ser empregado nas escolas, tal conceito passou a ser considerado como uma doença, de sua vida.

Dessa forma, Dacroce e Nicoli, colocam que todos os comportamentos analisados detalhadamente. Quanto mais conhecimento se tiver sobre o processo de aquisição da leitura-escrita, mais preciso será o diagnóstico e caso o distúrbio se enquadra como dislexia deverá ter um atendimento específico.

A dislexia conceitua-se como um conjunto de sintomas reveladores de uma disfunção parietal ou parietal occipital, geralmente hereditária, ou às vezes adquirida, que afeta a aprendizagem da leitura num contínuo que se estende do sintoma leve ao severo. A dislexia é frequentemente acompanhada de transtornos na aprendizagem da escrita, ortografia, gramática e redação, ainda, a dislexia afeta os meninos numa proporção maior que as meninas. A dislexia é uma deficiência de caráter lingüístico, e que deve ser abordada, no sentido de desenvolver habilidades de linguagem, principalmente aquelas ligadas ao processamento fonológico.

Em termos clínicos, é usado o termo distúrbio de leitura-escrita, pois possível ou não a identificação precisa de suas causas. Porém, nem sempre se consegue detectar determinantes causas com segurança, mas é possível encontrar na história da criança e nas circunstâncias atuais de sua vida, um somatório de fatores que podem ter uma forte correlação como as limitações apresentadas e trabalhar no sentido de e ou minimizar os déficits relativos ao processamento fonológico.

\section{3.-Metodologia.}

Para o desenvolvimento deste estudo se utilizou do enfoque qualitativo do tipo bibliográfico. Uma vez que o método qualitativo serve para compreender um problema de caráter humano e, ou social González, Fernandez e Camargo (2013). Ainda, 0 modelo bibliográfico fundamentar 0 estudo em idéias e ou teorias já 
concebidas sobre a temática elaborada para que se possa analisa-las e surja novas análise a partir das mesmas.

\section{4.-Discussão dos Resultados.}

A aprendizagem depende de uma habilidade tão complexa quanto a de ler e escrever depende de uma série de fatores que, funcionando de maneira integrada e independente, tornam possível tal aquisição pela criança. Entre os fatores mais importante pode-se citar a capacidade de usar a linguagem e de conhecer suas características, a inteligência familiar, as condições afetivas, o interesse e motivação para novas aprendizagens, assim como a qualidade da intenção escolar. Alterações em alguns destes fatores pode prejudicar no processo de desenvolvimento.

Quadro 1: Diagnosticando as dificuldades de aprendizagem: Leitura e escrita.

\begin{tabular}{|c|c|}
\hline Atividades: & Habilidades de: \\
\hline $\begin{array}{l}\text { Para que a leitura } \\
\text { ocorra, é preciso } \\
\text { compreender se há } \\
\text { uma relação entre } \\
\text { os símbolos } \\
\text { (significantes) e } \\
\text { aquilo que eles } \\
\text { simbolizam } \\
\text { (significado). A } \\
\text { criança precisa: }\end{array}$ & $\begin{array}{l}\text { - Compreender o papel da escrita enquanto um sistema de } \\
\text { representação da linguagem oral e seus usos sociais; } \\
\text { - Ser capaz de usar e compreender linguagem; } \\
\text { - Reconhecer os sinais gráficos e diferenciá-los entre si; } \\
\text { - Compreender que a escrita é organizada especialmente de um } \\
\text { modo particular, seguindo uma direção da esquerda para a } \\
\text { direita, tanto na formação das palavras, na formação das } \\
\text { sentenças assim como na estruturação geral do texto; } \\
\text { - Reconhecer um conjunto de letras como uma palavra escrita e } \\
\text { transformá-la na palavra correspondente na oralidade; } \\
\text { - Compreender o sistema ortográfico, ou seja, o conjunto de regras } \\
\text { que regula a transformação de sons em letras e letras em sons a } \\
\text { passagem do oral para o gráfico e vice-versa; } \\
\text { - Compreender o papel da pontuação na organização e } \\
\text { significação do texto; } \\
\text { - Buscar a compreensão do texto; } \\
\text { - Buscar as intenções e o ponto de vista de quem escreveu, e } \\
\text { - Ter uma postura de refletir ou pensar sobre o que foi lido. }\end{array}$ \\
\hline $\begin{array}{l}\text { Crianças com } \\
\text { pouco domínio da } \\
\text { leitura apresentam } \\
\text { as seguintes } \\
\text { dificuldades: }\end{array}$ & $\begin{array}{l}\text { - Não conhecimento ou pouca familiaridade com os símbolos } \\
\text { gráficos, o que provoca dificuldades de reconhecimento e } \\
\text { diferenciação entre os mesmos, assim como sua correlação com } \\
\text { o som correspondente; } \\
\text { - Falta de fluência, isto é, as dificuldades para reconhecer ou } \\
\text { discriminar as letras acabam por alterar a fluência ou fluxo } \\
\text { continuado da leitura; } \\
\text { - Velocidade da leitura; } \\
\text { - Lenificada em razão das dificuldades em lidar com os símbolos } \\
\text { gráficos; } \\
\text { - Rapidez, dificultando a compreensão do que está escrito e, em } \\
\text { geral, acompanhada de uma série de alterações como omissão, } \\
\text { substituição ou distorção das palavras ou trechos do texto; } \\
\text { - Não-compreensão ou desconhecimento do sistema de pontuação } \\
\text { e de seu papel na estruturação dos textos; } \\
\text { - Folhas de compreensão; }\end{array}$ \\
\hline
\end{tabular}




\begin{tabular}{|c|c|}
\hline & $\begin{array}{l}\text { - Empregos de estratégias inadequadas de interação com o texto: } \\
\text { - Leitura estritamente limitada ao sentido literal das palavras; } \\
\text { - Leitura acentuadamente dedutiva, com o leitor pouco se } \\
\text { prendendo ao texto e, praticamente, procurando "adivinhar" o que } \\
\text { está escrito. }\end{array}$ \\
\hline $\begin{array}{l}\text { Algumas } \\
\text { capacidades } \\
\text { necessárias na } \\
\text { escrita: }\end{array}$ & $\begin{array}{l}\text { - Compreender a escrita como um modo de representação } \\
\text { da linguagem oral; } \\
\text { - Conhecer as letras e o valor sonoro das mesmas; } \\
\text { - Identificar, na fala, os sons que formam as palavras e fazer } \\
\text { a correspondência entre sons e letras, o que implica a } \\
\text { consciência fonológica; } \\
\text { - Compreender que existe uma variação entre o modo de } \\
\text { falar e o modo de escrever; }\end{array}$ \\
\hline $\begin{array}{l}\text { Conhecer o } \\
\text { sistema } \\
\text { ortográfico da } \\
\text { língua } \\
\text { portuguesa é } \\
\text { necessário: }\end{array}$ & $\begin{array}{l}\text { - Identificar a existência de sons que são representados por } \\
\text { - uma única letra; } \\
\text { - Identificar a existência de sons que podem ser } \\
\text { representados por diversas letras; } \\
\text { - Identificar a existência de letras que podem simbolizar } \\
\text { mais do que um som; } \\
\text { - Dominar o uso da linguagem; } \\
\text { - Compreender o papel da pontuação e as formas de } \\
\text { - } \text { organizar os textos: } \\
\text { - Blanejar, antecipar e desenvolver uma narrativa; } \\
\text { - Considerar coesão e clareza no relato; } \\
\text { - Auto corrigindo-se, sendo capaz de reescrever o texto; } \\
\text { - Diferenciar entre os "estilos" típicos da expressão por meio } \\
\text { da oralidade e os "estilos" característicos da expressão } \\
\text { escrita. }\end{array}$ \\
\hline
\end{tabular}

Fonte: Dacroce e Nicoli (2014).

A memória é outro fator que prejudica o processo de leitura, na qual dificulta a retenção e a compreensão daquilo que foi lido. Porém, é importante lembrar que a memória não é um depósito de palavras que ficam estocadas para serem processadas. Quando lemos ou ouvimos não é possível guardar tudo o que foi lido ou dito na sua seqüênciação, mas conseguimos guardar ou reter a essência daquilo que foi dito e é isso que é necessário. Assim, da mesma forma que a leitura não corresponde a uma mera decodificação dos símbolos gráficos, a escrita também não se reduz ao processo inverso de codificação, ou melhor, de simples transformação de fala e escrita. Embora, a escrita corresponde a um sistema de representação da oralidade, ela não se limita a ser uma transição daquilo que é falado possuindo características próprias que precisam ser compreendidas pelas crianças que aprendem a escrever. 
É possível observarmos uma variedade de dificuldades em relação à escrita que pode variar em termos de extensão e profundidade. Podem apresentar problemas de ordem ortográfica ou limitações significativas em todos os aspectos envolvidos com 0 domínio da escrita. Para compreendermos a origem de tais dificuldades é necessário levar em consideração a natureza e as próprias características da linguagem escrita.

Muito se acredita que a aprendizagem da leitura e escrita depende do desenvolvimento de algumas habilidades tidas como pré-requisitos que garantem a prontidão para a alfabetização. Entre usar habilidade pode-se citar a coordenação motora. (Motricidade fina); a percepção visual e auditiva; a dominância lateral e 0 conhecimento de noções espaciais "direita e esquerda".

Tais habilidades são necessárias mais não suficientes. A escrita possui características próprias enquanto sistema de comunicação que divergem daquelas características típicas da oralidade. A escrita exige novas formas de raciocinar e de organizar o pensamento. Dessa forma, não bastam habilidades perceptivo-motoras, mas 0 desenvolvimento de formas particulares de pensamento e de simbolização implícitas na escrita e que não são necessárias na oralidade. Podemos descrever mais alguns dos problemas encontrados na escrita:

Conhecimento elementar das relações entre letras e sons;

Falta de compreensão ou de domínio do sistema ortográfico;

Dificuldades para organizar o texto espacialmente e para empregar a pontuação;

Dificuldades na construção de narrativas que podem ser caracterizadas por ausência ou falhas de planejamento ou antecipação, por ausência de clareza e coerência, por limitações na capacidade de desenvolver ou explorar um tema ou, ainda, em razão de limitações de ordem gramatical; Não-conhecimento ou domínio ainda elementar dos estilos próprios da escrita; Ausência dos procedimentos de autocorreção ou de reescritura do texto.

\section{5.-Conclusão.}

De acordo com o estudo percebeu-se, que, para a criança aprender a ler e escrever, ela precisa desenvolver novos modos de representar e compreender a realidade. $\dot{E}$ preciso que ela tenha uma boa capacidade de compreensão e expressão oral uma vez que as habilidades exigidas para 0 domínio da leitura-escrita não estão implícitas, no uso da linguagem oral. É que ela desenvolva formas particulares de interagir com textos escritos, assim como desenvolver novas maneiras de se expressar, de acordo com os modos próprios da escrita. Ainda, no ensino aprendizagem da leitura e da escrita, muitas crianças apresentam dificuldades para evoluir neste processo. Neste caso, se faz necessário se fazer inferências para a atenção diferenciada e ou até individualizada que diz respeito ao processo de aprendizagem da leitura e da escrita.

Deste modo, se faz necessário entender a dificuldade e 0 grau de dificuldade que 0 aluno apresenta se está relacionada diretamente a ela mesma em quais dos 
aspectos o maior problema como: nos déficits, percentuais, insuficiência no desenvolver, da fala, distúrbios emocionais e assim por diante. Assim é possível compreender a respeito da linguagem, principalmente sobre os problemas de ordem metodológica, de ordem social e econômica, e a questão que envolve o próprio dejeto a ser conhecido, ou seja, a linguagem escrita com suas peculiaridades. Assim sendo, os profissionais da educação devem manter-se enquanto mediadores fazendo inferências junto a criança para melhorar a aquisição da leitura e escrita, para que 0 significado possa ser construído no que diz respeito aos processos cognitivos e linguísticos necessários para que a criança deixe de ser unicamente falante de uma língua, mas torná-lo escrevente da mesma língua.

Contudo, quanto mais conhece a respeito da natureza e complexidade da linguagem escrita, pode-se cada vez mais entender as transformações que ela exige para melhor atuação na prática para saber como funciona este processo na mente de cada criança. Assim sendo, aumenta-se a capacidade de analisar e compreender os distúrbios que afetam a aprendizagem da leitura-escrita.

\section{6.-Bibliográfia.}

Antunha, E.L.G. (2014). Dislexia: implicações diagnósticas. (ABD). São Paulo: Associação Brasileira de Dislexia. S/d. Série ABD, folheto $n^{\circ} .6$.

Bossa, N.A. (1994). Psicopedagogia no Brasil: contribuições a partir da prática. Porto Alegre: Artes Médicas.

Dacroce, M,. Nicoli, V.V. (2014). Informe Psicopedagógico de uma avaliação institucional e informe Psicopedagógico de um estudo de caso clínico. Revista FIGEEA, p. 77-121. N.3. Sinop: Imprenorte.

Fagali, E., Vale, Z. (1994). Psicopedagogia institucional aplicada à aprendizagem escolar: dinâmica e construção na sala de aula. 4. ed. Petrópolis: Vozes.

González, J.A.T., Hernández, A.H., Camargo, C.B. (2013). Aspectos fundamentais da pesquisa científica. Granada: Adiciones Adeo.

Pain, S. (1995). Diagnóstico e tratamento dos problemas de aprendizagem. Porto Alegre: Artes Médicas.

Revista, (1998). Associação Brasileira de Psicopedagogia sobre a Dislexia. V.17. n.46. ABP: Novembro.

Scoz, B.J.L. (1994). Psicopedagogia e realidade escolar: o problema escolar e de aprendizagem. 5. ed. Petrópolis: Vozes.

Visca, J. (1987). Clínica Psicopedagógica epistemologia convergente. Porto Alegre: Artes Médicas. 